\title{
A Sense of Presentation: Hotta's Maxims
}

\author{
Kuniyoshi L. Sakai \\ Department of Basic Science, Graduate School of Arts and Sciences, The University of Tokyo, Tokyo, Japan
}

I had my first experience of scientific research in Yoshiki Hotta's lab while I was an undergraduate and graduate student at the Department of Physics. From Hotta, I learned not only how to perform research, but how to present a result most effectively. Based on his philosophy about scientific presentation, I have introduced Hotta's maxims in a chapter (§5, "A Sense of Presentation-Skill in Communication") of my popular book on science ${ }^{(1)}$ written in Japanese, which is translated here for the first time. The original Japanese sources cited in that book will not be referenced here except for Web sites. For those who can read Japanese, I would recommend Hotta's book ${ }^{(2)}$ published recently, which is full of his wit and charm. I hope that my contribution based on Hotta's maxims is helpful for young students, as well as for senior or professional researchers who are in the position of raising young and ambitious scientists, ${ }^{(3)}$

\section{PHILOSOPHY FOR RESEARCH PRESENTATION}

No scientific research is complete by itself. Research is materialized only by publishing its results. Publication or presentation of research is therefore the most challenging aspect of scientific activities.

Academic journals abound in the world, and there are as many scientific papers as stars in the sky. Writing a paper by oneself, however, is a demanding job. Because we are responsible for representing our work to the scientific community, we have to have confidence that we are undoubtedly world-class specialists in the field covered by our paper. We thus need to write a paper with high concentration and attention comparable to that which we have devoted to our research itself.

You may consider presenting your research as fundamentally the same as writing a novel or giving a theatrical performance. A paper, even if it is written by multiple authors, clearly reflects the process of their thought. In an oral presentation, a speaker plays the roles of both a leading actor and a director, so to speak. This does not mean, however, that we can write our paper or give our presentation in any way we like. On the contrary, we should not forget that our paper or presentation is intended to communicate precisely what we want to represent (or results of our research, in our presentation) to readers.

Whereas I emphasize that research itself is "selforiented," the philosophy for research presentation should be thoroughly "other-oriented", i.e., from readers' or the audience's perspective. You can do your research by yourself, but the publication (presentation) of your research requires both author (speaker) and readers (audience). Cultivating your skills in communication to others is thus fundamental to the philosophy for research presentation.

\section{PUBLISH OR PERISH}

Let me first clarify what publication precisely implies in an academic world. The term manuscript refers to unpublished materials. In contrast, a preprint refers to a copy of a manuscript for proofreading before it goes into publication, and a reprint (also called "offprint") refers to a republished edition or a separately printed article from a periodical. Manuscripts are strictly distinguished from publications. Any material that is not published in the form of book or journal article, including a privately published material, is not recognized as a paper published. Of course, an article appearing on a personal Web site is not recognized as an "academic paper." A doctoral dissertation is, however, recognized as an official academic paper even if unpublished, and it can be cited in an academic paper since a university or research institute accepts it officially.

There is an English idiom that goes, "publish or perish." This is a harsh maxim that tells us that we have no choice but to perish if we do not publish our papers. Even the best idea is not publicly recognized, if it is not actually published as a paper. This is because science is not a world of self-satisfaction. As Michael Faraday, a British physicist, has said, "Work. Finish. Publish."

Received 7 November 2011; accepted 15 November 2011.

Address correspondence to Kuniyoshi L. Sakai, Department of Basic Science, Graduate School of Arts and Sciences, The University of Tokyo, 3-8-1 Komaba, Meguro-ku, Tokyo 153-8902, Japan. E-mail: sakai@mind.c.u-tokyo.ac.jp 
There is always an exception to the rule, however. Henry Cavendish, another British physicist, who displayed his talent in experimenting in physics, published only a few papers himself. The results of his experiments remained unknown without being evaluated at all until his laboratory notes were later published by James Clerk Maxwell. Many of his results went ahead of the times, including the measurement of the universal gravity constant and the discovery of the inert noble gas. In memory of such achievements, the Cavendish Laboratory, which was named after him, was established as the Department of Physics at Cambridge University.

Cavendish was a man of strong character. He was one of a few scientists, who did not care about public reputation at all and also were able to look at himself with eyes of a strict scientist. I am not sure if this has anything to do with his extreme misanthropy. There are many episodes of this, such as devoting himself to research without taking a step outside his home or firing his housekeeper just because she came across him in his estate.

Except such an extreme case of Cavendish, we are all bound to the "publish or perish" maxim. I remember well that Hotta often mentioned this maxim to get my results published.

\section{PRESENTATION OF SCIENTIFIC RESEARCH}

There are three fundamental points for the presentation of scientific research.

First, it must be accurate. Accuracy takes the highest precedence in the presentation of scientific research. Obviously it is against the ethics of scientists to distort the truth deliberately, or to make a wrong statement inadvertently, even when the presentation is addressed to specialists or the general public. But being accurate goes beyond the accuracy of what we present, because the accurate information must be correctly perceived by readers or the audience. If any misunderstanding arises, unless readers or the audience have a malicious intent, it should be caused by shortcomings on the part of a speaker, due to a lack of accurate explanation. When we realize this, the accuracy of our next presentation will certainly improve.

Secondly, it should be accessible. Our presentation needs to be as accessible as possible. Nothing can be communicated to the audience, unless it can be understood by them. It is in fact very easy to present technical contents in technical terms. If the presentation is inaccessible, it should be caused by shortcomings on the part of a speaker for not explaining in an accessible manner. When we realize this, the accessibility of our next presentation will significantly improve. Accuracy, however, should not be sacrificed for accessibility; accuracy has thus higher priority than accessibility.

Thirdly, it should be short. The shorter our presentation is, the better; for we should not have readers or the audience waste their valuable time or cause them unnecessary pain. Nothing is more important than arriving at our conclusion quickly, just like the "light-speed yose (end game)" of the shogi player Koji Tanigawa. A short talk has an advantage of being easier to recall, since it is focused. Accessibility, however, should not be sacrificed for brevity; accessibility has thus higher priority than brevity.

These three principles mean nothing more than putting ourselves in readers' or the audience's shoes, i.e., presenting from others' perspective. Of course, it is assumed that a speaker has a precise understanding of what he/she is going to talk about. The better we understand the materials we cover in our presentation, however, the more likely it is that we take them for granted. This creates a psychological blind spot. That is, we are unlikely to realize that "others do not necessarily take them for granted." It is very difficult to switch from the speaker's to the audience's perspective.

This psychological blind spot about others' perspectives has something in common with magic or conjuring tricks. Once you know the secret, you will be convinced that events that actually occur can all be rationally understood because they follow laws of physics. However, you will not readily realize that "others do not necessarily take them for granted." Beginners in magic thus tend to evaluate the quality of a magic trick by the complexity of its mechanism, as they do not understand how the audience is surprised by a magic trick based on a simple mechanism. No matter how complicated a phenomenon you see is, it will not make the audience wonder, if they can feel its artificiality.

Michael Faraday, who was known to give excellent talks for the general public and children alike, such as "The Chemical History of a Candle" for his Christmas lectures at the Royal Institution, noted as follows.

"The lecturer should give the audience full reason to believe that all his powers have been exerted for their pleasure and instruction."(4)

That is, exerting all our power for the interest of others leads to an excellent research presentation.

\section{DELBRÜCK'S MAXIMS AND HOTTA'S MAXIMS}

According to Hotta, Max Delbrück gave the following two conditions for giving a good talk:

1. Assume complete ignorance on the part of the audience.

2. Assume infinite intelligence on the part of the audience.

Delbrück, who always sat in the front row during every seminar, was feared for walking out of the room during a talk if it was uninteresting. A speaker was reported to have fainted on such an occasion. 
In addition to Delbrück's maxims, Hotta's maxims given below are also important.

1. Assume complete ignorance on the part of the audience. (This is same as Delbrück's maxim.)

2. Assume infinite diversity in the audience's intelligence. (This is different from Delbrück's maxim.)

3. Make sure that individuals of the audience can reach levels one step higher than their own levels of understanding before the talk. (This is new.)

Hotta further explains as follows.

"It is obviously very difficult to meet these conditions in giving a talk. On second thought, before worrying if any of the audience may have a low level of intelligence, one should expect that some of the audience are wiser and have greater intelligence than the speaker himself/herself. One should give a talk that inspires such individuals to reach a level higher than the speaker's. That is precisely the point of giving a talk. True communication will be established, when the speaker himself/herself reaches new understanding after receiving feedback from such individuals."

Messages one gets by listening to a talk are called "take-home messages." We should make an effort to give a meaningful talk, which provides messages that highly intelligent people are willing to take home.

\section{PRESENTING RESULTS OF RESEARCH}

Presentation and publication of the result of scientific research by and large take place in the following three stages:

1. presentation at academic conferences,

2. paper publication, and

3. public release.

A presentation at an academic conference is intended to show and discuss the latest findings, and it covers a paper that has not yet been finalized (in progress or under review). In a general session at an academic conference (except a symposium), we should not, in principle, present a result that has already been published and become publicly known. That is, the first and second stages must not be reversed. I say "in principle," because a paper publication unavoidably precedes a conference presentation if a paper is published after the deadline for the registration of a talk (with a title and abstract) and before the conference presentation.

Scientific journals often release online versions of papers (electronic files in the HTML or PDF format) on the Internet prior to their printing. There is an agreement that one must not release the results of his/her research in newspapers, periodicals, or the Internet, until the day on which the online version of the paper is released (which is called the "embargo date"). That is, stages 2 and 3 must not be reversed. This is intended to protect the profit of publishers of journals and, at the same time, to guarantee enough time for a news reporter to write an accurate article.

Presentations at academic conferences are classified into two types based on how they are made: poster presentations and oral/platform presentations. A poster presentation enables us to have discussion with the audience assembled before a poster board on which we attach our materials, exchanging ample information with them, as we can explain our research in accordance with the interest and question of each of the audience. We can repeat a poster presentation each time a new audience comes, whereas we only get to give an oral presentation once.

You may think that an oral presentation is less demanding for a speaker in terms of efficiency, but it requires more elaborate preparation, because a speaker has only one chance to give the presentation. Slides used for an oral presentation need to be prepared in such a manner as to make them easy for the audience to see and as accessible to the audience as possible.

\section{A PAPER IS EVERYTHING}

When I was a graduate student, my adviser (Yasushi Miyashita) said to me, "Useless data remain useless, no matter how much they are accumulated." "Useless" data that fail to exhibit an expected effect are called negative data. Nothing, indeed, follows from negative data. On the other hand, publishing negative data may spare other experimenters from repeating the same mistakes. As a matter of fact, a report has been published with the title "Report of the Study Group on the Use of Knowledge of Failures: For the Positive Use of Unsuccessful Experience."(5)

Repeated experiments carried out over sleepless nights using the most expensive experimental equipment and the world fastest computer, however, mean nothing if they do not yield interesting results. The value of scientific research is completely independent from energy devoted for it. In addition, the most marvelous result yielded will not be properly communicated to other researchers, if the paper reporting it is not well written. Ultimately, "a paper is everything." What follows is a part of the passage from Michihiro Matsuda's Close-up Magic describing the "points of performance."

"Thinking from the perspective of the audience means to have a capability to look at oneself with the objective eyes of a third person. An amateur magician is interested more in how he/she performs a magic than in how his/her magic appears to the audience. 
'People are impressed to see a painting drawn on the humblest canvas, if it is a beautiful painting. Nobody, however, even looks at a painting drawn in a luxurious studio by a painter in a velvet smock using the most expensive paints in the world, if it is an uninteresting painting. It is the painting that people are interested in seeing.'

This is a saying by Dai Vernon. Magic is the same as painting."

It is the same with research. It is only the paper that people are interested in reading.

\section{APPROPRIATE QUOTATION}

A quotation in a paper of a passage from a publication is regarded as plagiarism, if its source is not clearly indicated. It is very important to have the correct knowledge about an appropriate quotation. A clear explanation is given by Japan Uni Copyright Center ${ }^{(6)}$ as follows.

"Before quotations, there must be an author's passage or publication, which is the side of quoting text. 'Quotation' is one of the exceptional clauses of the copyright law that allows the author to use without permission another's publication to the minimal extent, only when it is indispensable (e.g., used as evidence) for the development of the passage. With such legitimate quotation, it is allowed neither to alter the content to be quoted nor to excerpt only its preferred parts to distort the original point. It is also required to indicate clearly the source including the title and authors of the publication quoted."

It is thus illegal to copy the whole article and reproduce it in a book or on a Web site, without the permission of the author of the article even if the source is clearly indicated. It should be also remembered that a copyright does not perish even when a publication containing the article in question goes out of sale or print; it remains protected for a period (of 50 years under the current law) after the death of the author.

The "Article 32" of the Copyright Law of Japan, which specifies "quotation," indicates as follows.

"It shall be permissible to use quotations from a publication already made public, provided that such use is compatible with fair practice and does not exceed the extent justified by purposes such as news reporting, criticism, or research."

According to the Japanese version of Wikipedia (as of 2006), the "fair practice" is summarized as the following five requirements.
1. There must be a necessity to quote a publication, as well as a necessity for the extent of quotation. It is also required that the text, in which a quotation is made, has originality. It does not qualify as quotation simply to copy a whole passage after noting, "There is a passage that follows."

2. The text and quotation are in "superordinate" and "subordinate" relations, respectively, both qualitatively and quantitatively.

3. A quotation should be clearly distinguishable from the text.

4. A quoted passage is a part of a published work.

5. The source is clearly indicated (the "Article 48" of the Copyright Law of Japan).

The last requirement, clear indication of the source, may be widely known as a part of the minimum requirement. Fewer people, however, may correctly understand the "necessity" of quotation and the "superordinate/subordinate" relations between the text and quotation. Furthermore, it should be particularly noted that a quotation is inappropriate, if it is not clearly delimited or if it is made from an unpublished private article (diary, private correspondence, etc.) without the permission of the authors.

Even if the text and quotation are in superordinate/ subordinate relations quantitatively, we had better assume that there is a certain limit to the length of the quotation. A quotation that is too lengthy tends to be considered the same as a mere duplication. Regarding the maximum length allowed for a normal quotation, South End Press (Boston, MA) clearly indicates the following criterion in every book it publishes.

\footnotetext{
"Any properly footnoted quotation of up to 500 sequential words may be used without permission, as long as the total number of words quoted does not exceed 2,000. For longer quotations or for a greater number of total words, please write for permission to South End Press."
}

Thus in English, the criterion for quotation is about 500 words. One criterion set by Chuko Shinsho (Tokyo, Japan) is that "a quotation exceeding one page should be avoided as much as possible." This point needs attention when a quotation is made in a Web document or handout, as it tends to be given less attention, since the concept of "page" is not so relevant with such documents. I have received an assignment paper for my class that copied an entire article from the Internet without the indication of its source. I was horrified, although it was the work of a college student. Of course, I gave an $\mathrm{F}$ to the paper but received no complaint, presumably because the student may have felt guilty. I only hope that the student will take a lesson from this and not repeat the same mistakes. 


\section{DIFFERENCE BETWEEN PRINTED PUBLICATIONS AND THE INTERNET}

The Internet drastically changed the world of academic publishing. Now we can read papers in a variety of journals on our desk without walking around in a large library. We live in an age where we can learn of a new discovery reported on the other side of the earth in real time by a slight move of our fingertips and without using our feet.

The obvious advantage of the Internet is rapid distribution of information. It has now gone beyond convenience and become indispensable to search for necessary information among a huge number of papers and databases that keep growing rapidly. Most scientific journals have adopted "Online Editorial System" via Internet for authors and reviewers, and registration for academic conferences has gone online.

In exchange for convenience, however, Internet communication sacrifices reliability in communication. No one may believe any longer that all information obtained from the Internet is correct, but to what extent can Internet information be said to be reliable? It is difficult even for the most reliable Web site to eliminate errors completely. Official Web sites of publishers, responsibly and appropriately administered, make the same papers that appearing in their scientific journals available in the form of electronic files, but we can't tell whether a personal Web site is reliable. The administrator of the site may have arbitrarily "edited" papers and uploaded them on his/her site, and such editing can change them for the better or the worse.

In addition, the judgment of reliability depends not only on the party transmitting relevant information but also on the ability and knowledge of the party receiving it. This is because the reliability of information obtained depends greatly on how well a site viewer can sift information. We have to be wise enough to begin with in order to become wiser through the Internet.

Then, in what ways does information on the Internet differ greatly from information in printed publications such as books and periodicals? The greatest difference lies in the presence or absence of anonymity, review, and storage. A scientific paper contains the authors' names, is reviewed by the referees and editors, and is stored as it is for a long period of time. As the names of the authors and publisher (journal) are indicated on publications, their reliability is guaranteed by the judgment and responsibility of the authors and publisher. The publication of a book or paper full of errors will put in question the judgment not only of its authors but also its publisher. A paper is also examined for the reliability of its contents by being read by multiple persons other than the authors, including reviewers, editors, and proofreaders. All versions of a paper including its later revisions are preserved for record. Furthermore, as publications in printed media are preserved in libraries for a certain period of time, everyone can read them to confirm their contents anytime afterwards.

In contrast, with an article released on the Internet by an individual, it is often difficult to specify the name of its author. In addition, it is not subject to review, and it may be changed or deleted before we know. Consequently, even if we publish a scientific discovery on our personal website, it is not recognized as a scientific achievement. The fact that individuals can freely express themselves on the Internet, which is one of its advantages, conversely puts the reliability of articles on the Internet into the peculiar state of being dependent on individuals' judgment. However pertinent an article may appear, it is often unclear who is responsible for the article and to what extent the article is reliable, as its author remains anonymous. In addition, on the Internet, one cannot only readily release information but also easily revise or delete it. It is impossible to require that all information on the Internet, which changes every instant, be recorded on disks.

We can find, every day, someone who tries to make his/her opinion appear as if it were right without revealing who he/she is (and thereby avoiding proper academic discussion) by using "Internet forums" or "reviews" at bookstore sites, which can catch the eyes of many people. What is more, it is possible to pretend one is an "expert" in the relevant area by making an anonymous post. It goes against the ideal of publishing culture and natural science to accentuate differences in opinions and positions in science sensationally by using the Internet. The importance of the traditional "publication" of scientific papers has arguably become clearer by the very emergence of the Internet.

\section{PASSIVITY TO ACQUIRE INFORMATION, AND DEVALUATION OF INFORMATION}

Although searching a Web site by key words may seem to be an active behavior, but it is in reality a fundamentally passive one. Checking links in the list of search results is not so different from zapping TV channels to kill time. Unless we stop searching, we will be overwhelmed by the enormous amount of information on the Internet. Whether or not we hit the right site we are searching simply depends on the performance of a search engine, not on our wisdom.

Such passivity to acquire information brings a clear disadvantage to education, such that students will stop thinking. When a question arises, students would start searching on the Internet before they think about it. If they successfully hit a site that contains the necessary information, they may feel "lucky"; but by then they have already given up thinking. If they further keep repeating such passive browsing, they may acquire a large amount of superficial knowledge; but they will lose the habit of thinking. The only 
way to securely establishing knowledge is to complement imperfect information by pondering over their questions. An excessive absorption of passive knowledge might cause them to lose their scientific mind.

We can easily obtain various pieces of knowledge through the Internet, to be sure. The easier it is to obtain information, however, the less its value will be. For instance, suppose someone has made the same contents as the textbook for some correspondence course freely available on the Internet. Then, no one will pay for the correspondence course any longer; this is a clear violation of copyright. The value of information arises precisely because it contains knowledge that is not available elsewhere. What if more and more sites started to offer free contents appropriate to beginners for a variety of courses and areas of study offered at school? Even lab classes and seminars could be realized virtually on the Internet to a certain extent, if several cases of expected results were prepared. Then, textbooks would no longer sell and there would perhaps be no need to pay expensive tuition to attend lectures and seminars at the university.

The process of taking time to understand knowledge, discuss it with instructors and friends, or doubt it, is much more important than knowledge itself. The harder it is to obtain knowledge, the more room there will be to cherish, develop, and enhance its value. No matter how much we search for superficial knowledge, we may not necessarily achieve deep understanding. It would be regrettable that the Internet, which should be a treasure of knowledge, had devalued knowledge because of its convenience. The Internet is neither a magic wand nor Doraemon's "fourdimensional pocket." If anything, the Internet is only a popularized "melting pot of information."

From time to time, let's free ourselves from the Internet and take the time to read original papers and books carefully. In order to absorb the latest knowledge in science, we need sufficient time to digest it. We had better try to understand rather than know something.

\section{CHECKPOINT CALLED "PEER REVIEW"}

Even if papers go online and the value of information undergoes rapid changes owing to the Internet, the extremely human system for reviewing papers is expected to continue in the future. The examination and evaluation of a paper or application for a research grant by researchers in the same field are called "peer review" (i.e., reviewing by colleagues). As this system reflects the fundamental idea for evaluating the work of a researcher, let us look a little more closely at its procedures.

A couple of reviewers (who review a paper) whose names remain anonymous to the authors (whose paper is being reviewed) are appointed by the editor or editorial review board. Thanks to anonymity, a reviewer can highly praise or severely criticize a paper without any future troubles. If a reviewer were not anonymous, bribery could soon be rampant and an evaluation could be bought by money. On the other hand, there remains a risk that a malicious review can be given by exploiting anonymity.

With scientific journals, the names of authors seldom remain anonymous to a reviewer. In natural sciences, results newer than those covered by a paper often have been mentioned at an academic conference at the time when the paper is reviewed, and papers by those belonging to an authors' research group are most frequently cited. A review will soon identify authors even if their names are made anonymous. On the other hand, in the case of a piece of work in literature that is one of a kind, reviewing it with the author's name remaining anonymous can enable proper evaluation unaffected by the author's reputation.

Normally, no compensation is paid for reviewing; being able to know new ideas of colleagues is itself a reward. An excellent paper is very stimulating, and we can learn even from an immature paper as "an object lesson." It is a waste of time, however, to read too poor a paper, which makes the authors lose their credibility.

The process of reviewing, but not its purpose or philosophy, might be similar to that of a trial in the court. An author is like a "defendant," and reviewers are like "juries" or relentless "prosecutors." It is a little unreasonable to compare an author who has done nothing wrong to a defendant, but there is no other choice. The "judge" is of course the editor of a journal.

An author has an obligation to respond "truthfully" and faithfully to all questions or doubts by reviewers. If the author cannot respond, this itself constitutes a reason for rejection. Of course, when the author should make a refutation or is imposed an unreasonable demand, he/she has to counter in a logical manner like a competent lawyer. Since the reviewer's profile is invisible to the author, the latter has to have a solid command of logical thinking and argumentative techniques. Conversely, the author does not have to explain anything about what the reviewer did not ask about. We will lose if we lose our confidence and flee before being chased.

If an issue is not resolved upon response by the author to the reviewer, the reviewer can continue to pursue the issue. That is, if the reviewer is not convinced, so long as the editor admits the necessity for continued examination, the review process can continue for years. Sometimes the author may be asked to conduct a duplicate or additional experiment within the limited period of 3 or 6 months. New questions after the initial review are prohibited, however, since things will be out of control if a review starts indicating new issues about existing data.

In a highly competitive area or with a journal with many contributors, the decision for "acceptance" is seldom made immediately, although the notice of "rejection" may come immediately after the initial review or even without review. If the paper is, unfortunately, "rejected," we have 
no other choice but submit it to another journal. The most frequent decisions are "acceptance upon revision." If we get this reply, we have successfully cleared the first stage. After making the required revisions, we have to resubmit the paper with a separate list in a question-and-answer format indicating which parts of the paper have been revised, and in what way. Then the second stage of review begins. By undergoing such peer review, a paper is sure to become more readable and precise. This is the greatest purpose of peer review.

If everything goes well, a paper may sometimes be accepted within a month after submission. Sometimes, however, it may take years before the paper is finalized after repeated struggles, involving additional or duplicate experiments for years or unreasonable interference in review. If we submit our paper to a journal at a high level, we can receive a valuable opinion, as the level of its reviewers is also high. The competition, however, is intense with such a journal, since it is popular. Even if we submit our paper to a journal at a lower level, it does not mean our paper is more likely to be accepted, since a terrible misunderstanding could occur due to the lower level of reviewers. What is most important to a researcher is "never to give up until our paper is accepted." We will thus experience a drama with ups and downs until our paper is finalized.
In this way, the results of our research are published and our efforts for long years finally come to fruition.

Declaration of interest: The author reports no conflicts of interest. The author alone is responsible for the content and writing of the paper.

\section{REFERENCES}

Sakai, K. L. (2006). The work of scientist-How is the creativity emerged? [Japanese]. Tokyo: ChuoKoron-Shinsha. ISBN 4-12-101843-5, 340 pp.

Hotta, Y., \& Sakai, K. L.(2007). Gene, brain, and languageScience cafe for pleasure [Japanese]. Tokyo: ChuoKoronShinsha. ISBN 978-4-12-101887-8, 244 pp.

I would like to thank Joseph Kruempel (Journal of Neurogenetics Editorial Office), who is a young scientist as well, for his valuable suggestions on the manuscript. I also thank Yash Hiromi for his preface and many comments, which surely made my contribution more accessible to the readers.

http://en.wikiquote.org/wiki/Michael_Faraday

http://www.mext.go.jp/b_menu/shingi/chousa/gijyutu/001/ toushin/010801.htm

http://www31.ocn.ne.jp/ jucccopyright/ 